\title{
Providing a Uniform Design Experience in an Undergraduate Mechanical Engineering Program
}

\author{
Filippo A. Salustri and W. Patrick Neumann \\ Department of Mechanical and Industrial Engineering, Ryerson University \\ salustri@,ryerson.ca, pneumann@,ryerson.ca
}

\begin{abstract}
The design experience of $3^{\text {rd }}$ year undergraduates in Mechanical Engineering at Ryerson University, and the assessment of student design work, was found to be disjointed and highly variable across the program. To attempt to address this, the authors are constructing courseware to help instructors of non-design engineering courses embed rich and consistent design projects into their courses. A "lightweight" Fast-Design process was developed. Course-specific design project examples of the process are being developed for five $3^{\text {rd }}$ year courses using this design process. Current versions of all courseware are freely available. This paper details the nature of the courseware and how it was designed, developed, and deployed for the project. To date, one case has been deployed, two developed, and two more are under development. While results are so far only anecdotal, there is reason to believe that our approach can noticeably improve the design experience of students in nondesign engineering courses.
\end{abstract}

Keywords: engineering design, courseware, design project, curriculum design.

\section{INTRODUCTION}

Over the last several years, the Department of Mechanical and Industrial Engineering at Ryerson University has gradually adjusted its undergraduate Mechanical Engineering (ME) curriculum to accommodate changes to $\mathrm{CEAB}$ regulations on design. The general curriculum structure that emerged includes a $3^{\text {rd }}$ year without a dedicated design course. Instead, several $3^{\text {rd }}$ year courses include substantive topically specific design projects in non-design engineering courses (e.g., Machine Design ${ }^{1}$, Vibrations, Mechanics of Machines, Control Systems, etc.).

An ad-hoc department design committee was charged in 2014 with reviewing the state of design in the ME curriculum. This quickly zeroed in on examining what if

\footnotetext{
${ }^{1}$ Despite the course's name, the authors are adamant that there is no "design" in "machine design."
}

anything needed to be done to assist instructors using design projects in those courses. The authors, who both teach " $100 \%$ design" courses, investigated the matter and discovered what could be perceived to be shortcomings in how those $3^{\text {rd }}$ year design projects were being delivered: instructors with little design background or training were uncomfortable teaching design; design experiences and approaches were heterogeneous; and instructor expectations and assessments of student work were extremely variable.

To provide a more consistent design experience, the authors have undertaken, with the approval of our Department and support from the faculty, a pilot project to develop courseware for design projects in non-design engineering courses.

\section{PROJECT SCOPE}

The authors realized we could not impose on instructors to alter their lesson plans significantly. Our ME curriculum is already quite full. Most of the instructors involved have extensive and time-consuming research programs and did not have the resources to engage in extensive course re-design. Many instructors had relatively little experience teaching design (compared to the authors). Also, teaching assistants for such courses are not hired for their ability to grade design exercises; this leads to shortcomings in assessment of students' design project work.

We also realized the $3^{\text {rd }}$ year design projects we were targeting were smaller-scaled and more field-specific (e.g., vibrations) than the ones to which we were accustomed in our own semester-long design courses, which takes a more holistic view of the engineering design task.

Finally, the courseware the authors already use in their design courses was inappropriately complex and onerous for these smaller projects; it simply was not reasonable to expect students to execute a "full" design project when only $25 \%$ of their grade would be attributed to it.

Thus, new material and a new approach needed to be developed, which we pursued using a "participatory design" approach in which course instructors would be in- 
volved in the development of the courseware that the authors would offer to them.

\section{SOLUTION CONCEPT}

Since the authors' existing courseware is too complex for smaller design projects, we would need to devise a new, "lightweight" design process that could be applied to short (1-4 week long) topic specific projects. The process would have to be consistent with the existing courseware used in the authors' design courses, but stripped down to its most essential qualities. We call this process Fast Design because we intend it to be executed in a relatively short timeframe as opposed to the full, semester-long process that the authors use in their own design courses. Fast Design includes four major design activities: problem analysis (including usage scenarios and requirements generation), embodiment (including ideation and concept design), evaluation (of design concept feasibility), and refinement and iteration. We assume that detailed design has been covered separately, as part of the target courses into which Fast Design is to be injected. Fast design can be thought of as a "lite" version of the full process, to which students have been already exposed. While it eliminates most of the tools used in the full process (e.g., weighted decision matrices, pairwise comparison, systems block diagramming, etc.) it preserves the underlying philosophy; namely, that a designed artifact will be an intervention intended to quantitatively ameliorate a situation. Justification of all design decisions also remains central to Fast Design; as the instructors often tell their own students, no design decision is a good one if it isn't justified. Furthermore, to the greatest extent possible, Fast Design encourages students to think about the implications of their design - no matter how restricted by course subject the design goal may be - to the broadest possible scope, including societal, environmental, and financial aspects.

To help ensure a uniform design experience, Fast Design must have a single specification across all courses. This creates a mismatch, however, in applying the process in courses with very diverse goals: how does one apply a generic design process to a project in, for example, a vibrations course? Given the scope as described above, we could not expect individual instructors to develop the necessary materials needed to ground Fast Design in their own courses. We needed a way to show both instructors and students how Fast Design worked in specific courses.

The authors thus came to the idea of having a worked example for each course to complement a generic process manual. Each worked example would document the application of Fast Design to a project compatible with actual projects given in each specific course. The examples would satisfy the instructor's learning and teaching objectives for the actual course project; therefore, so long as the project objectives did not change, the worked example would remain relevant and useful regardless of how in- structors might change the actual projects they gave their students. Students in a given course would be given both the Fast Design manual (the current version, v0.8, is freely available at https://goo.gl/BaVllK) and the coursespecific worked example so that they could see how design could be applied to the subject matter of that course. The aim was to help instructors provide a consistent engineering design experience compatible with their course content and with the other courses the students were taking at minimal extra workload in course development.

At first, the authors thought that each course would end up with its own worked example; a vibrations course might use a simplified damping system for a tall building, while a machine design course might use a humanpowered winch/dolly for moving heavy equipment. However, the authors then considered having a single product at the heart of all worked examples, and having each example consider only certain aspects of the product according to the course topic; e.g. Vibrations. We have come to believe that this approach has merit. Assuming a suitable single product could be found, the use of the same single product across courses could help show students how the individual subject areas are all necessary to develop a fully realizable product. In this way we aim to foster a broader systems view of the engineering design process amongst the students. We hope that this would emphasize to students the necessity of fully integrating their knowledge - something fundamental to their $4^{\text {th }}$ year Capstone design projects.

In this project, we chose a kitchen blender as a reasonable example design project to use as a basis for all the Fast Design worked examples. A blender can be treated in a number of domains pertinent to mechanical engineering: vibrations, structures, fluid flow, heat and mass transfer, manufacturing and assembly, etc. It can also be treated from an ergonomic point of view, thus bringing the "human element" into the overall design considerations. The worked blender examples are meant primarily for students, rather than instructors, to show them a complete application of Fast Design in a course-specific context.

The authors realized that building worked examples for each course would require significant time - more time than we ourselves could dedicate. We were also concerned that we might not remember enough of our own undergraduate education to carry out the analytic parts of the examples. Since our target courses would be those in $3^{\text {rd }}$ year, we realized we could hire $4^{\text {th }}$ year students and graduate students to construct the worked examples under our supervision.

To this end, the authors applied for and secured $\$ 17,000$ funding from the Dean of the Faculty of Engineering and Architectural Science via the Dean's Teaching Fund. The funding period was originally one year but has been extended by an extra year (details provided below). This funding is intended to provide the equivalent of 
research assistantship funding for senior undergraduates to develop the worked examples for the kitchen blender.

Finally, and again as a result of the lack of engineering design process knowledge of the $3^{\text {rd }}$ year course instructors, we needed to provide instructors with assistance to assess their students' design work. This served two purposes: (a) helping to ensure a uniform design experience for students, and (b) lessening the burden on the instructors, who may not be familiar with design assessment methods.

The authors have devised a simple and general rubric where each of the four tasks of Fast Design are rated on a 0-4 scale roughly corresponding to the letter grades as defined in Engineering at Ryerson University. The current version of the rubric is available at https://goo.gl/QNXstc. For each task, guidance is provided in the form of questions that the assessor should answer of a student team's work. The assessments for each task are then averaged to produce a single assessed value for the student project. The instructor is then free to fold that assessment into an overall project grade in whatever way he or she sees fit. Adjusting the examples, and evaluation participatively with the instructors as required was part of the authors project implementation strategy.

We note that the Fast Design courseware is completely independent of other assessment criteria that may pertain in a given project. For example, in a design project for a course in vibrations, one may reasonably expect students to have to calculate various system behaviours and responses to demonstrate their understanding of vibrations. This is not covered by any of the material we provide to the instructor. It remains solely in the hands of the instructor to decide (a) how to grade those course-specific elements and (b) how to weight the design components of the project against those other, analytic components. Instead, the examples and related Fast Design process aims at design process consistency across courses.

\section{DEPLOYMENT}

The authors intentionally avoided detailed, wideranging plans for deployment of Fast Design because we recognized that we really had no sense of what would work in each of the different courses in which Fast Design could be applied. We did imagine, however, that each course would present its own distinctive challenges. Our flexible and interactive approach was intended to help us meet each instructor's particular needs. We also did know that we would have to depend on the instructor's expertise in their own course's specific content - this necessitated a participatory design approach where instructors would be intimately involved in the development work. At the same time, however, we had to be mindful not to take up too much of the instructors' time, which is always in too short supply.
The first step was to identify candidate $3^{\text {rd }}$ year courses in Mechanical Engineering. We used information from our last $\mathrm{CEAB}$ accreditation report to find all $3^{\text {rd }}$ year courses with $25 \%$ or more design in our department. Of the 10 such courses, the instructors of six of them have indicated preliminary interest in immediately participating in our project. The six courses - MEC514 (Applied Thermodynamics), MEC411 (Mechanics of Machines), MEC613 (Machine Design I), MEC616 (Fluid Mechanics II), MEC709 (Control Systems), and MEC721 (Vibrations) - became the initial targets for the application of Fast Design.

As of this writing, the authors have recruited instructors from all six of these courses to pilot the Fast Design process. In one case, the instructor of MEC514 (Applied Thermodynamics), though enthusiastic to participate, was concerned that the large size of the class could have disastrous consequences if something went wrong with the Fast Design trial. He therefore suggested piloting Fast Design in his 4th year Thermal Power Generation course (MEC810), which is much smaller, with the intention of expanding Fast Design to include MEC514 in the future. We accepted this proposal. To date, the Fast Design Process has been implemented in one course, MEC613 (Machine Design I). Development in the other five courses is ongoing.

The authors will begin with a relatively detailed explanation of the MEC613 case to explain the overall process. We will then describe progress so far in the other five courses in broader strokes.

Since neither of the authors had executed a project like this before, we began by approaching a single instructor, that for MEC613 (Machine Design I), via email. We provided the instructor with a short description of the overall project, invited them to participate, and suggested an introductory meeting to kick it off. The instructor agreed.

The meeting took the form of a semi-structured interview. The goals of the interview were (a) to ensure the instructor understood and approved of the scope and goals of our project with respect to his course, (b) understand how the instructor saw design as an element of their course and how they taught and assessed it, (c) establish the instructor's expectations and role as a participant in this project, and (d) establish requirements of a blender example problem such that it remained consistent with the specific topic and course learning objectives.

Due to scheduling constraints, we needed two separate meetings, nearly two weeks apart, to complete the semistructured interview. There were several outcomes. Most importantly, the instructor remained interested in participating in the project and understood its potential benefits to his students. He shared with us sample design projects and student reports from previous years; these would inform our development of the blender example problem statement. They also served as a focus for us to elicit the instructor's learning objectives. These objectives had to 
apply to the blender example, so it was vital for us to understand them.

Once we had agreed on goals and learning objectives, we asked the instructor to suggest a few students who had completed the course well, with the intention of hiring one of them to execute the blender design and develop the worked example.

While selecting one of those students and submitting the hiring paperwork, we developed the actual blender design problem. We met with the instructor again to verify that the blender problem statement was consistent with his expectations for the course. There were two minor iterations of changes to the blender problem before it satisfied the instructor's needs. A draft of the blender problem definition for MEC613 is available at https://goo.gl/mcIiR6. The instructor also suggested that the authors review the actual project he intended to use in the coming offering of the course, to make sure he "had the design piece right," which we did.

The student we eventually hired had excelled both in MEC613 and the authors' own $2^{\text {nd }}$ year introductory engineering design course, and was able to quickly and effectively work the Fast Design process for the blender. After two iterations of changes, the example was presented to the instructor. While we were prepared for the instructor to request various changes to the extent and level of detail of the example, the instructor was very pleased with the result. The current version of the worked example is available at https://goo.gl/HjJomw.

The final element of the MEC613 case, the assessment rubric, was developed last, largely because the authors expected that the rubric would have to be framed with respect to specific learning and teaching features of MEC613 about which we were unaware initially.

Once the blender example for MEC613 was nearly completed, the authors reviewed the generic rubric described in Section 3. In light of our experiences with the instructor for MEC613, we simplified the rubric even further. We then reviewed it with the instructor. The instructor believed the rubric was specific enough to provide necessary guidance but general enough to give TAs who would use it the guidance needed to grade student work fairly and flexibly.

The instructor deployed the design project on schedule in the last month the Winter 2016 semester. At the outset, the instructor provided students with the Fast Design manual, the blender example problem, and its worked solution. About two weeks into the exercise, the authors met briefly with the instructor for a status update. The instructor advised us that few teams had started their projects. Salustri offered to host a short question and answer period about Fast Design at a mutually agreeable time. Such a session was held during a MEC613 lecture shortly thereafter. At that time, many students admitted that they had not yet started the project, and so had few questions. However, once one student "risked" asking about it, many other students asked questions too. Overall, the instructor and Salustri agreed that the question and answer session had served its purpose of promoting student enthusiasm for the project.

MEC613 student team reports were collected in the last week of the semester. Teaching assistants were charged with grading the reports per the rubric. We have not yet had an opportunity to review the results of those reports in detail. Nonetheless, the authors met with the instructor once final course grades had been submitted for a short debriefing. The instructor received no feedback from the TAs regarding the grading process - whether it was onerous or difficult to understand, whether the rubric "made sense" to them, etc. The TAs did not return the rubrics to the instructor; only report grades were provided. A review of the grades for the design components of the overall projects (i.e., excluding the analytic elements relating to course-specific knowledge) shows a range from $60 \%$ to $100 \%$. Most importantly, the instructor was pleased with how Fast Design fit into his course, and he reported looking forward to continuing to use it in future years in MEC613.

The other five cases of the application of Fast Design are not as advanced. In MEC721 (Vibrations), we have fully developed the blender worked example, but did not have the time to deploy the material for the Winter 2016 design project in that course. We (the authors and the instructor) expect to deploy it in Winter 2017. In MEC810, a blender problem statement has been defined and approved and the worked example is currently under development. In the other three courses, we are still scoping requirements, defining learning objectives, and developing appropriate blender problems.

\section{OBSERVATIONS AND DISCUSSION}

This pilot project was a learning experience for the authors as well as all the participating instructors. In this section, we discuss some of the major observations made during the project thus far.

One problem that greatly hindered the authors' progress in this project was the difficulty of scheduling meetings with instructors. Between the authors' own schedules and those of the instructors in the target courses, meetings often took many days to schedule. We could have sought funding to hire a project coordinator who could do all the planning and organizing for the cases; while this likely would have expedited matters, it would have also eliminated the possibility of hiring $4^{\text {th }}$ year students to write the worked examples. (We likely would have had to double our budget if we wished to hire a full-time coordinator, and that would have been impossible with the funding sources available to us.) We considered using $4^{\text {th }}$ year students a major learning benefit of our project, and so decided to manage, plan, and organize the project cases ourselves. 
This is not to suggest that rich interactions with instructors could have been avoided. It became quickly apparent to the authors that the only way the Fast Design project could possibly benefit non-design engineering courses was through deep involvement by the instructors. The meetings held with instructors yielded a wealth of course-specific information that was essential to develop meaningful courseware. The authors are convinced that little of use would have come of the project without implementing a participatory design process.

An early step in each case was to review existing design projects. In all cases, the authors found that the projects were generally over-constrained and over-simplified, to the point where we were concerned that some projects might not meet CEAB criteria as "design problems." For instance, there were cases where design problem statements were so over-specified as to permit a single "solution." This underscores a continuing difficulty that some instructors have in understanding the nature of engineering design, a situation that does not seem to have improved noticeably since the beginning of the NSERC CDE program ${ }^{2}$. However, we believe that this is mostly due to the personal history of the instructors, who had been "raised" academically in an era where design was largely ignored in engineering and so lack the knowledge skills and resources to engage in this development work unsupported.. We note again that all the instructors we approached were enthusiastic to be involved with the Fast Design project, and believed that our project goals were good ones.

We sometimes had a difficult time eliciting from the instructors the learning objectives of the projects they deployed. We are not sure why this is, and hope to investigate this point further.

Another problem we faced more often than we would have thought was that instructors did not understand that the blender would be only a worked example and not the actual project their students would do for credit in their courses. It was almost as if they could not understand how one could describe a design cogently enough to be an example that students could follow. The best, albeit still not perfect, method we found to explain this feature of the Fast Design project to them was to use the textbook from their own course, point to any worked example in the book, and tell them "There: like that; that's what the blender problem and its solution will be like. Students will be able to review a complete solution to the blender problem as an instance of the Fast Design process." We are not sure why this was such a difficult concept for instructors; it may have been a result of some preconceptions of the instructors, a lack of clarity by the authors, or

\footnotetext{
${ }^{2}$ Salustri was involved with the development of the CDE program as early as 1998, and was also a founding member of CDEN, which joined with C2E2 to form CEEA.
}

other factors we have not yet identified. We hope to try to find out in the future.

One aspect of the project that was surprisingly easy was finding $4^{\text {th }}$ year students that we were confident could execute the worked examples to our satisfaction and that of the course instructors. Perhaps it was just beginner's luck, but in all three cases where content has been or is currently being developed, finding an appropriate student took no more than one day in each case.

The authors have anecdotal evidence from $4^{\text {th }}$ year students that suggest they do not believe design "matters" in the $3^{\text {rd }}$ year curriculum. This may be the result of the inconsistent and highly variable approach taken by $3^{\text {rd }}$ year instructors. When Salustri hosted the question and answer session on Fast Design for MEC613 students, it appeared to surprise students that they were expected to be able to design given the $2^{\text {nd }}$ year mandatory design course. It was almost as if they took the $2^{\text {nd }}$ year design course expecting it to be irrelevant to their subsequent studies. The authors need to examine this matter much more closely and determine if this is an actual effect or just an artifact of the anecdotal nature of the evidence we have. If the effect is real, however, the Fast Design initiative described here could be very useful to address this problem.

A significant organizational problem involved cases where instructors changed from one year to the next. The authors always operated on the assumption that whoever was currently teaching a given course would very likely continue to do so. However, in two of the targeted five courses, MEC616 and MEC709, this was not the case. For both these courses we discovered in early Spring 2016 that other faculty would be teaching them in the 2016/2017 academic year. This meant that whatever work we had started on Fast Design for those courses was essentially lost, and we would have to completely restart those cases once the new instructors, significantly slowing overall progress on the Fast Design project. In hindsight, the authors should have anticipated this. We have adjusted our initial semi-structured interview to try to find out the likelihood that a given instructor will teach a course for some reasonable length of time (at least a few consecutive years).

The authors note that as a result of the unforeseen delays we encountered, our Dean graciously extended our funding for another year, so that we can try to complete our initial plan of implementing Fast Design in between four and eight courses. Armed with this knowledge, the authors believe we are in a better position to meet our goals by this time in 2017 .

\section{FUTURE WORK}

There are a number of directions for future work based on the Fast Design project as described here. In this section, we will briefly discuss some of them. 
The question of maintaining teaching innovations in the face of changing instructors remains an open question. As evidenced by the cases of MEC616 and MEC709, changes to teaching staff can set potentially innovative projects back. While this sort of setback is unavoidable, we may use the Fast Design experience to help look for better ways to accommodate instructor changes while preserving successful teaching innovations.

The information we have gathered to date about the MEC613 case of Fast Design is rather cursory. We will be seeking to survey students, the teaching assistants, and the instructor more deeply as soon as possible to gather richer data about this case. We are arranging to have access to the actual project reports, so that we can see what the students were able to achieve and also investigate whether the assessment rubric was well-used by teaching assistants.

Based on the apparent success of the question and answer session hosted by Salustri for the MEC613 case of Fast Design, we plan on offering a question an answer session in all future cases of Fast Design. One problem with such sessions is that students can feel too embarrassed or self-conscious to ask questions with all their classmates listening. To try to address this, we will also offer instructors a "consultation" session where the authors will attend a lab/tutorial session dedicated to let teams sit with us, one-on-one, to discuss their projects.

As we execute cases of Fast Design and gather feedback from students, teaching assistants, and instructors, we expect we will have ample material to use to revise both the Fast Design process and the individual worked examples for each course.

If the Fast Design project successfully completes this pilot stage, we will first need to devise some more rigorous assessment process to measure more confidently whether Fast Design accrues benefits in non-design engineering courses.

In the long term, should Fast Design be determined to be useful within the Mechanical Engineering program, and if sufficient administrative support is available, the authors would like to expand it to other Departments at Ryerson University.

\section{CONCLUSION}

This paper presented an approach to create a more uniform design experience for undergraduate students in non-design engineering courses. The approach is based on developing design projects that are based on a lightweight design process and augmented with course-specific worked examples based around a single design artifact in this case a kitchen blender. The consistent examples provide a familiar and integrative context for students to consider the topic specific design requirements for each course. It also helps acts as a reference for the Fast Design process which the students are then required to apply to the course specific design assignment. While not definitively demonstrated, there appears to be reason to think this approach can provide benefits to students and instructors without necessarily placing an increased burden on the instructors

We recognize that the days of strictly separated disciplines in engineering are nearly over. The future of engineering education will likely involve more highly interdisciplinary courses. These courses will be difficult to offer given that most faculty members in engineering programs come from mono-disciplinary backgrounds. The kind of project described in this paper represents one scheme for promoting bleed-over between disciplines that may have been treated completely separately in the past.

\section{Acknowledgements}

The authors wish to thank the Dean of the Faculty of Engineering and Architectural Science (Ryerson University) for funding this project via the Dean's Teaching Fund. We also extend our sincere appreciation to the instructors who made the time to be our "guinea pigs" for this project, with little guarantee that their efforts would not be in vain. 